\title{
Packaging Features Effecting on Milk Buying Behavior in Karachi
}

\author{
Osaf Ahmed Khan ${ }^{1} \&$ Danish Ahmed Siddiqui ${ }^{1}$ \\ ${ }^{1}$ Karachi University Business School, University of Karachi, Pakistan \\ Correspondence: Osaf Ahmed Khan, Research Scholar, Karachi University Business School, University of Karachi, \\ Pakistan.
}

Received: February 20, 2019

Accepted: March 10, 2019

Online Published: March 18, 2019

doi:10.5430/ijba.v10n2p129

URL: https://doi.org/10.5430/ijba.v10n2p129

\begin{abstract}
This paper examined the packaging features effecting milk buying behavior. Four packaging features were selected that included nutritional information, price, country of origin, \& quality standards, and their impact on milk consumption and purchase behavior is analyzed using Structural Equation Modeling. The study was carried out in urban areas of Karachi, among 318 respondents using Likert scale based questionnaire. The findings suggested that all four packaging features have a significant positive impact on consumers buying behavior. Consumers are attracted towards those products which provides enough and adequate amount of information on its products' packaging. Nutritional information is among one of the important element that needs more focus and it will surely results in a positive way to the manufacturers of dairy products. Hence, producers and marketers of milk should focus on their product's packaging features especially on the verbal element as a primary strategy in order to influences consumers buying behavior.
\end{abstract}

Keywords: onsumer-buying behavior, country of origin, nutritional information, price, quality standard, demographic characteristics, brand, advertisement, SEM

\section{Introduction}

\subsection{Background}

Milk is one of the most vital diet for mammals and it is irreplaceable because it's highly complex and nutritional composition. In mammals during early stages of new born mother's milk is the only source of food but it is slowly replaced by other mammals such as cows, buffaloes, goats and sheep's etc. Reason behind choosing milk is that it is as one category of dairy products, fit in to the group of basic daily-consumed products and reasonably high purchase frequency, and it's one of the products whose production and consumption is relatively high in Pakistan. With the help of this study we can find out several other factors which can be beneficial for organizations that the people in Karachi are literate enough that they can consume all the information which mentioned on packaging, on hoardings or any other sources from which a consumer can take information. What are their liking and disliking regarding products that are available in the market? In some countries there exist some factors that do not support the consumption factors. While domestic producers have put efforts to bring in those new encouraging aspects of technological advancement that helps in more efficient product lines, and also trying their best to improve the quality of milk that helps in satisfying consumers.

According to Economic Survey of Pakistan milk production in Pakistan is increasing and gross production of milk was estimated to be 56,080,000 tonnes. Local producers of are aiming to produce more high quality milk till 2020. Even though an upturn in milk and meat production, the prices have risen abnormally. Pakistan is the fifth largest milk producer in the world. Milk production is 28 million tonnes from 125 million heads. Milk is used for butter making, yogurt, drinking, tea, desi ghee. According to the reports milk consumption in Lahore is 2 to 3 million liters, whereas in Karachi is 4 million liters. The demand for processed milk has certainly risen its share in quality conscious consumers. Now there is a need to know the better insights and examine the consumer behavior since Pakistani consumers are becoming more educated and sensible in their choices. Since the disposable incomes of citizens are increasing; so consumers are willing to pay the premium prices for the products available in market. But in this study we are going to restrict ourselves only in Karachi. Due to massively aware consumers and market situations, consumers are in a position where they are decisive and prominent figure in the market so company's has to put them in front during their marketing efforts. For that reason, for the approval and success of any established marketing strategies \& tactics, well designed marketing mix and other promotional tools among consumers relies on 
the firm's ability to properly understand consumers need segments and correctly spot the individual factors and pinpointing those subconscious stimuli that forces consumers when purchasing products that significantly leads to satisfaction. In order to get the insights of individual's consumer behavior it requires an ongoing approach which must consist of very broad and strong subjects of marketing attention. With a population of more than 200 million in Pakistan, and rapid increments in the numbers, the consumption and production of milk is also experiencing positive trends in Karachi as well as in Pakistan, which requires a certain attention for scientific and examining approaches to uncover those factors which are contributing this favorable trend and creating robust effect on the milk companies in Pakistan. Differences in personal traits are a result of being in different environment interaction and they are connected to socioeconomic and demographics variables (income, sex, age, education level prices). A major proportion of milk is consumed in tea, which is a common drink, so milk is demanded by every household in the country. Consumers in Pakistan can be categorized as rural or urban. Major differences between the two are in their access to milk production, purchasing power, and taste preferences, while both share a very high preference for liquid milk, with some milk by-products such as lassi9 and yoghurt also in demand.

\subsection{Problem Statement}

Milk is considered to be one of the key elements of human's diet. In order to attract consumer and influence their buying decision companies do play with their packaging. The problem statement of this study is to find out whether such elements of milk which includes, Price Nutritional Information, Quality Standard and Country-of-Origin, impacts the buying behavior or consumers in Karachi or not. If yes, then which of the specified element has a greater influence on consumer buying behavior? Since Pakistan has lowest literacy rate and it has declined to 58\% from 60\% according to economic survey of Pakistan 2018. Since many people in Pakistan are not aware of milk importance in daily life and the factors which are important in the sales of milk. Since many local milk producers are not taking quality standards into considerations when it comes to giving quality milk to consumers which are mainly infants and kids because it is essential for their growth. When government announces the budget, Pakistan Dairy Association (PDA) also increases prices, without raising quality of the milk which they are providing to the consumers. This is why people are more inclined towards buying milk branded segment of milk. Branded segment carries wide range of information regarding different factors which may effects consumer buying behavior, and for better insights some users are not literate enough to interpret such knowledge and labelling of the milk packaging. So it is always a task for bug brands to dig out such factors that are now pushing consumer towards branded milk segments.

Since people of Pakistan in general are now looking to buy consumer goods which are coming from out of the country, so in case of milk consumption, people of Karachi are really into the outward sources of milk, which may result in cognitive thinking that this milk may get sour after opening even if the expiry date is mentioned.

Pricing also plays a significant role among people in Karachi, people tend to look for cheaper in terms of prices when alternatives are present; but is there a significant relationship between pricing of milk and consumer behavior in Karachi?

Now many products carry lots of information regarding nutritional component of any product because consumer is really getting more and more aware about health and the effect of the products that they are going to consumed. Since milk is a very complex and wholesome food so is there a necessary to put nutritional information on milk, which in case, it has to possess all the nutrients which are vital for human growth and development.

Quality Standard are must to follow in other countries regardless of the product. But in Pakistan especially in Karachi which is an industrial hub for the country, few companies' follows standard and protocols according to the industries., but many local milk farms usually don't have such machineries and adequate information and knowledge due to lack of education how to process raw milk, because if milk is not preserved and maintained at desirable condition, there is a chance that it's going to be sour. So is it mandatory for farms to produce milk by following standard and quality protocols?

This research will be focusing on what factors attract consumer towards it, when buying milk. In today's world with changing consumer's dynamics with stiff competition and highly saturated market; for any organization, it is necessary to understand consumers and his patterns, so that they are better in understanding and identifying those elements that effect his buying decisions for the purpose of creating an striking deal of products, associate services, communication means and supplementary marketing tools that would be suitable to customer's needs.

\subsection{Gap Analysis}

Socio-economical, psychometrics analysis and related work is already available throughout various medium as it is vital for marketing firms to know the exact consumption behavior of consumers and shoppers. Hong (2015) investigated that role of cultural, social, personal and psychological factors is impacting sales of imported formula 
milk in Vietnam is relatively high as compared to locally available milk. Related research that has been carried out previously was focusing on packaging elements and consumer behavior, according to previous researches packaging elements comprises of easy to tear, easy to hold, milk bottles, tetra pack, and verbal elements of the packaging color scheme (G. Gupta \& A. Kumar 2016).

A. Bousbia et al. (2017) examined the relation between dairy products consumption and consumer behavior due to the importance of these products and effect on economy; measured different socio-economic variable that defines different individual's behavior on the basis of taste, type of shop, health benefit, brand, origin, packaging and publicity. Each variable has significant impact on consumption apart from publicity. K. Kurajdova et al. (2015) investigated personal and psychological factors on consumer behavior regarding purchasing and consumption, and tried to uncover the relatively low consumption of milk among Slovaks as compare to other European countries. This study tried to find out the possible segmentation criteria for marketing firms in order to stimulate consumer to purchase and consume more milk.

B. Boniface \& W.J. Umberger (2012) investigated the drivers for increasing milk consumption among Malaysians by determining demographics variables such as age, ethnicity and attitudinal variables that has significant effect over consumer behavior regarding consumption. Adam \& Ali (2014) determine the impact of packaging on dairy product in Karachi. Getting deeper insights of packaging element that includes verbal elements such as color, shape, size, design packaging material, packaging size and packaging graphics. Furthermore, it also provide detailed result of verbal element of packaging which includes product information, and country of origin.

As it is observed by looking at different researches throughout the present literatures we found out that lots of work is available on extrinsic factors related to our work i.e. packaging, materials, consumption, cultural, social impacts, demographics etc. but not much work is done on intrinsic factors which are related to milk and associated with consumer's dynamics regarding this category.

This study not only focused on demographics segmentations, cultural, psychological, or keeping marketing techniques in scope, but it's going to dig out deep intrinsic factors that corresponds to the consumers in Karachi, as milk is usually consumed on daily basis, but what factors are motivating shoppers to buy it on daily basis and to what extent they play a role during purchasing. The above mentioned studies do not shade light explicitly on quality standards, country of origin, nutritional information, but pricing is discussed in many papers but not much is present about consumers in Karachi, Pakistan.

This study is combing nutritional information, price, country of origin and quality standard and their effect on consumer's buying behavior in Pakistan's region specifically in Karachi. This study also suggested the impact of each variable over buying behavior which is going to be beneficial for marketing firms to analyze consumers and shoppers closely.

\subsection{Research Objectives}

Main focus of this study is to line out all the factors that are on top of the mind of consumers when they are in search of milk, keeping all the gaps in mind from previous researches we tend to look in to such factors from new perspective of statistical analysis. Major focus in this study is all about the factors that effect a consumer buying behavior, apart from that it will also enable us to look into demographics of the citizens in Karachi, how well they are equipped in terms of knowledge, education, their income or earning level. The vital purpose of this research study relies on some of the research objectives, which are defined as below:

- To find out the extent to which the information about milk enhance consumer's buying decision.

- To find out whether the nutritional information over milk packaging enhances consumer's buying decision.

- To find out whether the country-of-origin in milk segment influences consumer's buying decision.

- To find out whether quality Standards and protocols effect consumer's buying behavior.

- To find out whether pricing has any significant impact on consumers buying decisions.

\subsection{Significance of Research}

The essential and most important purpose of this research study is to find out the relationship between different factors of milk and consumer buying behavior. The other purpose of this research is to identify the factors which can affect the buying behavior of consumer more in accordance with the elements. This study will also help us to identify whether these elements of milk have an influence on consumer buying behavior or not, if not, then what other factors does consumer looks towards in when buying milk. The research study will help marketers and firms in order to 
design the product in such a way that will influence the buying decision of consumer. This study will also help consumers to realize the importance of nutritional information, price, country of origin and quality standard of the milk packaging that they should be look into before making a purchase. The research findings will also reflect how much does the factors of milk product's packaging have an impact of consumer buying behavior or does other factors of the packaging also impacts the decision process of consumer or not?

Pakistan Dairy Association (PDA) publish its reports time to time that's purely focuses on dairy sector and its growth over the years and problems faced by milk producers but doesn't include consumers and their related behavior and queries under its scope; if they intend to find out such underlying factor then this could be groundbreaking for milk producers and marketing firms to capitalize on issues and came up with possible solutions that may results in beneficial from commercial point of view.

\subsection{Research Question}

Milk is always considered to be one of the key elements of human diet and has an influencing factor that effect consumer buying behavior. To determine the consumer's buying behavior related to milk category, few questions arise in mind:

1. How much the milk influences the buying behavior of the consumer?

2. What are the factors that impacts consumer's buying behavior regarding?

3. Do the quality standards dominate the consumer's buying behavior?

4. Does Nutritional information on packaging influence consumer's buying behavior?

5. Does country-of-origin impacts the buying behavior of consumer?

6. Does price plays any role in purchasing decisions of consumers?

\subsection{Hypothesis Development}

The core purpose of this paper was to observe chosen psychological factors of milk purchase among peoples in Karachi in connection with their personal factors. Following our aims, we wanted to dig out specific intentions and obstacles of milk purchase among consumers of Karachi and relationships and dependencies between consumer behavior and 4 other variables. With the relationship between research question and research objective in accordance with the variables of this research study, the important and relevant hypothesis for this study are as follows:

H1: Nutritional information on the packaging of milk impacts consumers buying behavior.

H2: Milk pricing influence consumer's buying decision.

H3: Country-of-Origin on the packaging of milk impacts consumers buying behavior.

H4: Quality Standards of milk impacts consumers buying behavior

\section{Literature Review}

Milk represents one of irreplaceable and most vital food ingredients for all mammals. Since the beginning of the life of every single mammal kind, milk becomes essential and the only component of food income. For instance K. Kurajdováa et al. (2015) conducted a research in Slovakia. The main objective of that research was to find out the underlying factors which might be effecting the low production and consumption of milk in Slovakia, which was effecting individual's health and effecting Slovakia economy as well. The survey was conducted among 1033 respondents, results were classified into two categories i.e. motives and barriers to milk purchase. Personal motives which includes tastes, health, and usage versatility of milk receives higher positive response. The factor of health problems appeared to be prominent, whereas price and product availability were not been significant enough for respondents. However, this study didn't count buying behavior influence on milk purchasers. So, the question arises what could be the possible steps that marketing managers should take on potential segmentation on variables. The gap in this study is that it narrows down the behavioral characteristics on consumer behavior but theoretically there are many components of consumer behavior which can be included on possible segmentations.

Hong (2015) examined the detailed consumer behavior in formula milk market in Hanoi, Vietnam. This research examined 97 respondents over 4 factors (i.e. cultural, social, personal and psychological) and results shown positive influence on each factors regarding formula milk buying behavior. This research also expressed that domestic formula milk sales is lesser than imported formula milk. However, some factors exist that do not support domestic milk powder manufacturer in Vietnam. Cultural factor got positive response on buying intentions as kids are consider as a future of the family in Vietnamese culture. Social factor also has positive relation with buying intentions as 
children's nutritional need is taken serious in people. Personal factor also received positive response, it measured this factor on the basis of income, education, and experience of products, as well as price and economy also impact buying intentions. Psychological factors measured on the basis of quality, price brand and origin. Vietnamese people always preferred imported goods and products for better quality, better designed. Now a day, although the economy has developed rapidly and many goods and products have been produced in land, but the belief in imported goods with their well-known brand, origin of product and their quality is considered unchanged (Fulbright, 2010). The big issue in this research was time limitations and targeting only Hanoi but it encompasses all of the Vietnam.

A. Bousbia et al. (2017) examined the relationship between dairy product consumption and consumer behavior in Guelma, Algeria. Among 326 respondents, dairy product consumption behavior was assessed on the basis of yearly quantitative parameter. For perception analysis various socio-economic variable used to assess consumer behavior such as taste, health benefits, packaging, type of shop, brand, the origin of product and publicity. This study showed positive impact on taste, origin, brand, packaging and health benefit on consumer perception when buying dairy products. While milk consumption was effected by geographical location and children per house. Algeria's milk consumption is relatively high but this study didn't find any strong response from the region of Guelma.

Adam \& Ali (2014) investigated the packaging impact of dairy products and its underlying factors in Karachi with 384 responses. It showed significant positive response on different packaging types such glass bottles, tetra pack, packaging cap, rectangular packaging and convenience in handling except for milk in plastic bottles which negatively correlated with buying behavior. Whereas, verbal elements which includes branding, color, font style, product information, and country of origin were positively correlated. The weakness with that study was it was only related to household consumers. It does not include shop owners, who use packaged milk for commercial purposes. Moreover, this research is restricted to the buyers and consumers of packaged milk in Karachi only. Plus it doesn't shade light on new and improved packaging design for milk or dairy products.

L.T. Tuan (2012) examined that due to rise in imported powdered milk in Vietnam, local production hit economy as whole. 110 respondents responded that that product brand, advertisement, and country of origin are significant predictors of consumer-buying behaviors towards imported powdered milk, but sponsorship has no significant impact on buying behavior regarding powdered milk. This study is cross-sectional which may not provide certain evidence on the direction in which factors impact consumer-buying behaviors.

B. Boniface \& W.J. Umberger (2012) investigated the provocations of increasing dairy demand from 435 respondents by examining the factors influencing Malaysian consumer's consumption and perceptions of various types of dairy products, determining the relative importance of various product attributes \& information; and investigate factors influencing Malaysian consumers increasing demand for dairy products and fluid milk. The results backing the findings of researchers that propose demand for dairy products will continue to surge forward and supersede domestic milk supplies. This research was only conducted in urban city Kota Kinabalu, Sabah. This research only talk about fluid milk, but there are several types of fluidic milk available in the market such as pasteurized and UHT milk. Further research on different types of fluid milk, as well as the importance of shelf life, may give some new insight which will aid in domestic dairy industry.

According to G. Gupta \& A. Kumar (2016) recorded 60 responses which confirmed that product packaging plays vital role in impacting buying behavior. It indicated that several factors of packaging i.e. graphic, color, size, positioning, material of packaging, wrapper design, \& printed information are considered as important ones. However, the concern is it doesn't prove relationship between product quality and product packaging fully.

\subsection{Conceptual Framework}

Consumer Behavior is dependent on the marketing strategies, and it includes dimensions such as values, loyalty, motivation, satisfaction and etc. which enhance the consumer buying decision. Every factor associated with the product has a role to attract consumer towards it and communicate the message which influence the consumer buying decision while shopping. The consumer decision making is based on the five elements, identification of the problem, searching of information related to problem, find out or differentiate other alternatives, make a purchase, and post-purchase behavior. These are those key elements which are included in making a purchase, therefore when making a purchase, packaging of the product can also attract consumer towards it and force the consumer to think about it. Usually labelling on packaging comes under the umbrella of verbal elements of the packaging, but our aim is not to discuss packaging itself. Four primary motives which we are going to discussed in this paper are Nutritional Information, Quality Standard, Price and Country of origin. 


\subsubsection{Buying Behavior}

Consumer behavior is a complex pattern and sophisticated understanding for marketing researches, but simply defined; study of psychological, social and physical actions when people buy, use and dispose products, services, ideas and practices (Solomon, 2006; Blackwell et al, 2001; Peter and Olson, 2008). Consumer plays a vital role in marketing strategies of firms, so it essential for marketing teams to create a product or service that creates value for customers through which they can satisfy their need and achieve desired level of satisfaction. Buying Behavior of Consumer is influenced by many factors; it could be environment, music, light, odor, colors and etc. When we talk about the packaging, then consumer buying behavior is influenced by visual and verbal elements of the packaging. Visual elements of packaging include colors, size, image of the packaging and verbal elements of product's packaging include product information, nutritional information, country-of-origin, brand name and etc. Visual elements of the packaging are tend to be more focused when it comes to the low-involvement product category, on the other hand consumer pays more attention to the verbal elements of the packaging when it comes to the high-involvement product category. Jain (2010) published the four-category classification of factors or determinants, as he stated in his framework, consisted of economic determinants including factors like income, liquid assets, credit, living standard, government policy and economic conditions; than sociological determinants involving factors such as family, reference groups, opinion leaders, social class and culture; psychological determinants comprising of factors like motivation, perception, image, learning, attitudes, beliefs, personality and lifestyle; and finally personal determinants containing the factor of age, education, occupation, family life cycle, role and status.

(Valajoozi; Zangi, 2016) Consumer's behavior towards the selection of goods and services is considered to be one of the vital elements for big firms. There are three phases which makes up the consumer's buying behavior decision which includes making process before the purchase, decision making process while the purchase and decision making process after the purchase. Whereas, some researches also suggest that there are five processes includes in consumer's decision making process; problem identifying, gather information related to product/service, evaluate alternatives, make a purchase and post-purchase decision/dissonance (Adam \& Ali, 2014).

One of the basic questions that arise in the minds of marketer is what is the final reaction of the consumer towards the product/service after all the marketing efforts are put into effect? The answer of such types of questions will help the marketer to gain competitive advantage over the rivals and it will help them to surpass their rivals' in terms of market share and profit. One of the crucial difficulties faced by marketer while investigating the consumer buying decision is the impulse buying behavior. Impulse buying is defined as, "the buying of goods and services without planning in advance" (Oxford Dictionaries). Thus the impulse buying opposes all the decision making process and makes difficulties for the marketers in order to understand the buying behavior of consumers.

Another factor that makes difficulties for the marketer is the role of age of the consumer towards the information available on the product. Different age group people react differently according to their thinking process and according to their mindset and power of perceiving things. This factor can be seen in the age group of parents and children while making a purchase. The difference between the selection factor and things that attract both type of consumers towards it, can ease the marketer and the designers to make product's packaging in a way that in the end results in the form of sales and profit.

\subsubsection{Nutritional Information}

(Adam, Ali 2014) information labelling on milk not only allow consumer's mind in helping to make purchase decision, but it also helps in leaving a positive brand image after their experience with product, because it helps in retaining some of the information from previous buying cycle. Milk is like a gift from nature that possess the quality of whole food in itself. It is enriched with most of the nutrients that are vital for mammals and plays a crucial part during growth cycle. In Pakistan media is always trying to emphasize on the importance of milk, but still major portion of population don't consume it on daily basis. A. Alwis et al. (2009) nutritional content have positive (stimulating) impact and conversely health problems.

The National Dairy Council (2008) milk is considered to be one of the most nutritionally complex and balanced foods "containing a wide range of essential nutrients required for growth, development and overall health and wellbeing throughout one's life cycle". Based on their knowledge and experience people searching information about the product they intend to buy and evaluate them (Ziya et al., 2006; Solomon et al., 2006; Devine, 2005; Colonna et al., 2011).

Nutritional Facts or Nutritional Labeling of the product is a vital feature when we talk about the verbal elements of the packaging. Nutritional information totalizes the whole concept of health and nutrients. It also provides a 
consumer detail information about the product inside. Consumers used to go through a decision making process and the nutritional information about the product makes them to make a purchase easily. Nutritional information on the packaging of the product provide the detail knowledge about the nutrients includes in the product which includes, low saturated fats, cholesterol, fruits, vegetable, grains, sugar, salt and sodium which allows them to keep their healthy and risk-free diet. Consumers can also use the health claims which appear on the front of the packaging to know about the certain nutrients information to avoid risk and illness factor. Nutritional information does not only provide detail knowledge about the product's, but it also helps them to switch from 'unhealthy' product's category to the 'healthy' product category in no time, especially when we talk about the health care and consumable items.

If the product's is not labeled with the nutrients information, it is less-likely that shopper will make a purchase of that product. If the nutrient's information is not available on the packaging, shopper might be uninformed of the healthy benefit which a product contains. Nutritional information of the product allows consumer to make a purchase in no time.

\subsubsection{Country-of-Origin}

Insch and McBride (2004) discussed "three dimensions (design, assembly and parts), which could influence the overall product quality evaluation, and all three of these could originate in different countries". Chao (2001) found that Country of Design, Country of assembly and Country of Manufacture impact "consumers' perception of product quality and that consumers differ in the weight that they give to the different dimensions. Since its normal trait of human personality that they want to show off when they put something good, eat something good. Since milk is considered to be most uniform food, which you can find in any corner of the world, slight differences in taste may occur because of how people preserve it present it. There are few countries in the world, which have created certain kind of expertise in product categories and have built up their particular image (Keller, 2009). Based on this notion, consumers may make decisions to buy products with such national ties in order to portray a self-image and to fulfill the need. In addition, such strong positive associations and beliefs of consumers regarding various brands could create a point of difference regarding the country of origin (Keller, 2009). People in Pakistan now try to use more imported products, which significantly burden country's economy so keeping recent government initiatives of promoting local goods and services; but people still buys local fresh milk to satisfy their needs. "In addition to health importance milk has an economic significance, too. This means that milk plays a crucial role in the growth and development of not only human body but also national economy” (Kurajdova \& Petrovicova, 2015).

Buyers often make judgments about product quality and purchase value on the basis of extrinsic cues. According to Johansson et al. (1985), country of origin, COO, is an extrinsic information cue allowing buyers to make inferences about the intrinsic value of a product, this is why country of origin, an extrinsic cue, is often used buy buyers to judge foreign products (Ahmed et al., 1995). Chao (2001) recommended that "for the products originating from countries associated with unfavorable stereotypes, the priority should be given to attributes and benefits that are capable of countering the influence of country of origin. There are many countries in the world that have created expertise and certain type of products/product category. That some consumers associate a well-known brand such as Sony with its traditionally perceived COO (Japan) has been partially confirmed (Chao and Rajendran 1993; Maronick 1995).Based on this concept, many consumers become brand loyal and it becomes difficult for them to switch from the brand they usually buy. At the time of purchase, the country-of-origin can help the consumer to make a purchase as it has an impact on consumer's buying behavior. It was found that product's superiority comes at the first place in individualistic societies and domestic products come first in collective societies. In order to understand the packaging of the product, we can divide the packaging into two cues, Intrinsic cues and Extrinsic cues.

\subsubsection{Price}

P.T.T. Hong (2015) people look into price factor when they buy milk, it has a significant impact on buying behavior of consumer, and it also showed that for milk producers, if they set the right price as a result of that they may get substantial benefit from selling more milk to consumers. Since milk is a commodity which is purchased on daily bases to serve different needs of consumers, and due to rise in prices of milk it's somehow effected the consumer but there is no slump in consumption of milk, and rapidly increasing population demands more and more. "In dollar terms, the per capita income has grown by an impressive rate of $9.5 \%$ to $\$ 1,513$-up by $\$ 129$ per person in the outgoing fiscal year 2014-15, according to estimates" (Shahbaz Rana, 2015). So people are willing to pay more and more for better products and services to satisfy their needs. Results also signifies that foreign product are better in quality and in terms of branding and promotions but on the other hand it also suggested that the price of imported milk is higher than domestic produced formula milk. 
However, the number of people chose imported milk for their children is significant big with 58\% interviewees. This may come from the fact that consumers interpret higher prices as a signal of superior quality and lower prices as sign of inferior quality. In Vietnam, it is said that, parents prefer expensive milk as they think it is better to buy that than the cheaper ones that are available in the market because it may hinders their buying decision because of perceived quality. Additionally, consumers seem satisfied with the products that they have paid more to obtain. They think that: "Everything has their owned price". Thus, domestic firms and lower-price producers should consider if lowering prices is the right strategy for developing brand and gaining market share from foreign players or it just hurt the brand.

During shopping, consumers usually come across many product and its variants of milk on shelves, filled with domestic and foreign products. There is uniform competition for best site in supermarket between brands. Thanks to this product differentiation, milk market could be considered as a competitive market, and milk consumers have enough brands to select. However, it can be said that it is not a perfect market, because it is very difficult for consumers to access to product information (Fulbright, 2010). Before making buying decision, consumers want to screen product characteristics and quality. In fact, producers or sellers do not disseminate much information to the buyers. That study also entails that point that consumers also lack information about prices. They cannot gather enough information of prices to compare before buying. In addition, Vietnamese people have a habit of buying milk in smaller, local shops than in supermarkets, where prices are listed on the products.

\subsubsection{Quality Standards}

B. Bonaventure and W. Umberger (2012) and P. Senadisai et al. (2014) health, proportion between price and quality and knowledge about milk as main motivational factors influencing the purchase behavior of milk. Due to critical importance of milk and dairy product, its quality, safety standard and protocols are strictly followed by food regulatory authorities and federal government in different countries. Kumar and Babu (2014) realized a research on brand preference, customer satisfaction and influencing factors regarding dairy products purchase behavior in Pondicherry State, India. Through the research, they examined the importance of six selected factors, namely advertisement, brand preference, product availability, product pricing, product quality and product variety on consumer dairy purchase behavior.

Recent consumer research suggests that Malaysian food consumption is becoming increasingly diverse and consumers are growing more concerned about the quality, safety and nutritional content of their food (Ishida et al., 2003; Liana, Radam \&Yacob, 2010; Prescott et al., 2002; Rezai, Mohamed, \& Shamsudin, 2011).

To measure the quality of milk usually two parameters are monitored which includes total bacteria and somatic cells, these are used globally to evaluate milk quality in terms of appropriateness for consumption and processing the milk for dairy products. Globally, HACCP (Hazard Analysis Critical Control Point) is recommended for the management of commercial dairy farms and milk processing plants in order to produce high quality milk and dairy products. These safety measures and control programs are meant to avoid abnormal and unsafe milk and dairy products entering into food channels for human consumption. Many factors affect composition, yield and safety of milk, its production, manufacturing and marketing. A number of consumer characteristics such as socio-demographics (e.g. gender, age, income, education, presence of young children in the household, ethnicity), knowledge, attitudes and perceptions have been shown to influence Malaysian consumers" demand for quality-differentiated food products (Ong, Kitchen, \& Jama, 2008; Prescott et al., 2002; Quah \& Tan, 2010; Radam, Yacob, Siew Bee \& Selamat, 2010; Rezai, Mohamed, Shamsudin \& Chiew, 2010; Rezai, et al., 2011; c, Pani, Mansor, Elias, \& Sadek, 2010; Sheng, Shamsudin, Mohamed, Abdullah \& Radam, 2008).

Consumers now look at material quality to and perceive the product as a superior quality. It also suggested that testing of milk and dairy product should be carried out correctly by milk collectors and processors, since such systems are costly but it will provide benefits to everyone involved in the dairy industry. If milk producers and processors support each other with right supportive tools to yield quality milk and dairy products out in the market than they both can charge moderate price from the market. As a result of that when consumers perceive the product of highest quality and standard they will happily pay the price that producers are charging. Since milk is biochemically unstable that means it deteriorates rapidly if not preserved rightly.

According to Pakistan Dairy Association (PDA) many local producers are still far behind from the present day technology and not utilizing their full potential capacity of production, they use external hormones to stimulate cattle to produce more milk and sometimes one producer buy milk from other farms to fulfill his demand from his target market, which raises a question mark on the quality of that milk, because not many farms are utilizing and preserving the milk at ambient conditions which are necessary. Exposure is first component of consumer perception, when 
consumer is exposed to such information about the quality of milk, it will certainly help in getting their attention at point of sale which result in a stimuli that helps them in interpreting their experiences during previous buying decision. Once they are keep getting those repeated exposure it will eventually leads them to buy your product. According to the research in Hanoi $65.24 \%$ of parents have also monitored the quality as well as the effects of chosen product before giving next buying decision, it's related to psychological thinking of peoples which achieve the greatest value of mean when measuring quality as a factor when buying milk.

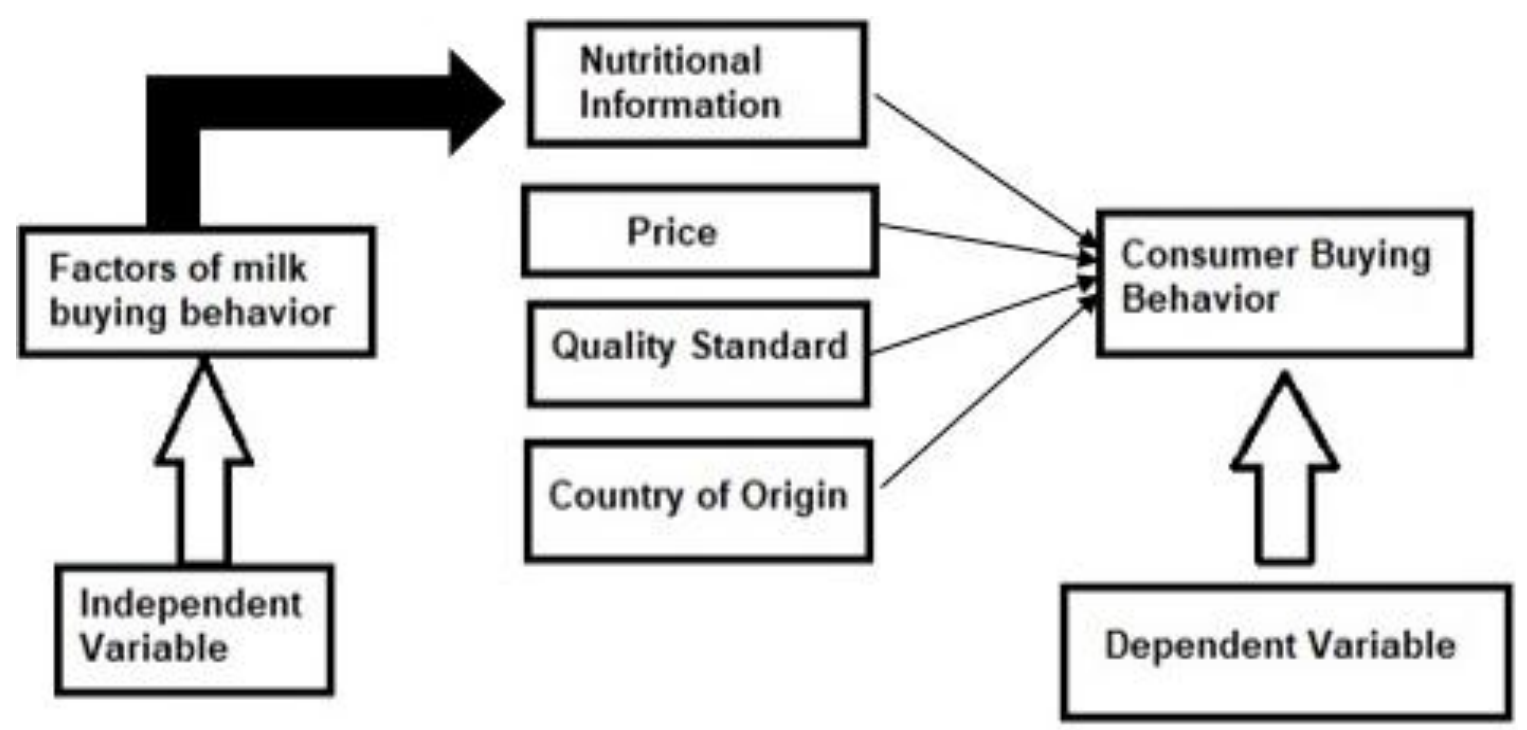

Figure 1. Model

\subsection{Hypothesis}

H1: Nutritional information on the packaging of milk impacts consumers buying behavior.

H2: Milk pricing influence consumer's buying decision.

H3: Country-of-Origin on the packaging of milk impacts consumers buying behavior.

H4: Quality Standards of milk impacts consumers buying behavior.

\section{Methodology \& Results}

\subsection{Data Collection}

The study was carried out in urban areas of Karachi, mainly North Nazimabad, Nazimabad, Gulshan e Iqbal, P.E.C.H.S, Gulistan-e-Jauhar, Malir and few other areas and questionnaire was also uploaded over Google Forms as well. The survey was conducted which comprises of several questions on each factors, among 318 respondents. Out of 318 responses 124 were collected from Google Forms and 194 were conducted on papers. Each respondents has to make choice based on likert scale ranging from 1 to 5, Strongly Disagree to Strongly Agree. Consumers perception about milk was tested based on different variables which are nutritional information, price, country of origin and quality standard; the questionnaire was comprises of quantitative and qualitative approaches.

\subsection{Sample Description}

Based on collected data, which was evaluated on SPSS, it was recorded that most of the participants are male with $53.1 \%$ and females are $46.9 \%$.

The largest group belongs to the age group of $18-29$ years old with $80.5 \%$, with $17.9 \%$ 30-49 years old group was second and the age group of 50-55 and above 55 years old are $0.6 \%$ and $0.9 \%$ respectively.

With $93.1 \%$ of the respondent's level of education is university, $5 \%$ of the respondent are from college, with $1.6 \%$ are from secondary level of education, and $0.3 \%$ is primary level of education.

The biggest pool in job status is belong to employed respondents with $55.7 \%, 38.1 \%$ are student, $5.3 \%$ are unemployed, and $0.9 \%$ belongs to retired respondents. 
Marital status comprises of $67.6 \%$ are single, $21.7 \%$ are married, $10.4 \%$ are engaged and with $0.3 \%$ is a single respondent with divorced status.

Income level's pool comprises of: $16 \%$ of respondent are earning below $15,000,14.8 \%$ are in $18000-29,999$ range, $21.1 \%$ are earning between $30 \mathrm{~K}-45 \mathrm{~K}, 19.8 \%$ are earning more than $45 \mathrm{~K}$ and $28.3 \%$ responses are N/A.

Table 1. Socio-demographic profile of the population and samples

\begin{tabular}{lll}
\hline Variable & Frequency & Population (\%) \\
\hline Gender & 169 & \\
Male & 149 & 53.1 \\
Female & & 46.9 \\
Age of Respondent & 256 & \\
$18-29$ & 57 & 80.5 \\
$30-49$ & 2 & 17.9 \\
$50-55$ & 3 & 0.6 \\
Above 55 & & 0.9 \\
Level of Education & 1 & \\
Primary & 5 & 0.3 \\
Secondary & 16 & 1.6 \\
College & 296 & 5.0 \\
University & & 93.1 \\
Job Status & 121 & \\
Student & 17 & 38.1 \\
Unemployed & 177 & 5.3 \\
Employed & 3 & 55.7 \\
Retired & & 0.9 \\
Marital Status & 215 & \\
Single & 33 & 67.6 \\
Engaged & 69 & 10.4 \\
Married & 1 & 21.7 \\
Divorced & & 0.3 \\
Income & 51 & 16 \\
Below 15,000 & 47 & 14.8 \\
18,000-29,999 & 67 & 21.1 \\
30,000 - 45,000 & 63 & 19.8 \\
45,000 or more & 90.3 \\
N/A & & \\
\hline
\end{tabular}

\subsection{Descriptive Statistics}

Table 2. Descriptive statistics

\begin{tabular}{lccc}
\hline & \multicolumn{2}{c}{ Mean } & \multicolumn{2}{c}{ Std. Deviation } \\
& Statistic & Std. Error & Statistic \\
\hline Verbal elements of the packaging attract consumers while buying any product. & 3.6478 & .05586 & .99613 \\
$\begin{array}{l}\text { Verbal Elements of the packaging are important factor in high involvement product } \\
\text { category. }\end{array}$ & 3.5629 & .05197 & .92672 \\
$\begin{array}{l}\text { Verbal Elements of the packaging are important factor in low involvement category. } \\
\text { Nutritional Information impacts consumers buying behavior }\end{array}$ & 3.1761 & .05021 & .89538 \\
$\begin{array}{l}\text { Nutritional Information about the milk gives consumers detailed insight about the } \\
\text { product inside. }\end{array}$ & 3.9119 & .05285 & .94240 \\
\hline
\end{tabular}


Labeling of milk packaging is an important part of product.

$3.9308 \quad .05024$

.89597

Pricing impacts consumers when making purchase.

$4.3333 \quad .04721$

.84186

Pricing impacts consumers when purchasing milk.

$4.0377 \quad .05132$

.91525

Does premium pricing impacts milk sales?

$3.8994 \quad .05106$

.91047

Does lower price effects the success of milk?

\begin{tabular}{ll}
$3.5755 \quad .06649$ \\
\hline
\end{tabular}

1.18573

Pricing and Brand's name impacts consumers buying behavior.

$4.0943 \quad .05319$

.94847

Country-of-Origin impacts consumer's buying behavior.

$3.7736 \quad .05192$

.92579

Milk with country-of-origin's label attract consumers more.

$3.6258 \quad .05896$

1.05147

Countries with negative image impacts consumers buying behavior.

$3.8176 \quad .05395$

.96209

Countries with negative image affect the milk sales.

$3.7547 \quad .05463$

.97422

Eastern products over Western Products attract consumers more while purchasing milk.

$3.6258 \quad .06610 \quad 1.17877$

Dairy Products with Halal tag regardless of any country-of-origin impacts consumers buying behavior.

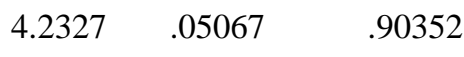

Quality standards and protocols impacts consumer's perceptions.

$4.1698 \quad .04463$

.79595

Quality Standards plays vital role in milk category.

$4.3553 \quad .04785$

.85336

Milk with renowned brand name are priority of consumers while making a purchase.

$4.1604 \quad .04743$

.84589

Milk with good taste and smells impacts consumers.

$\begin{array}{ll}4.3333 & .04417\end{array}$

.78765

Quality packaging impacts consumers while purchasing milk.

$4.3428 \quad .04517$

.80542

As from above analysis it can be observed that for each question's the mean value is above 3, which is mentioned as neutral in the questionnaire but all the values are indicating that most of the respondents are agreeing with the each question regarding milk purchasing. But only in the question of nutritional information \#3 the value is 3.1 , this question is related to low involvement product, so it can said that people usually don't look at information when buying low involvement product.

\subsection{Inferential Statistics}

To measure the impact of price, nutritional information, quality standard, country of origin over consumer buying behavior several tests were applied to check the reliability and effects of each factor. Cronbach's Alpha is used to test the reliability of the data on each factor. Inferential statistics helps to make inferences and conclusive evidence from the sample data drawn from a population. Results from the remaining items produced a reliable model and considered for reliability and validity test and path analysis.

3.4.1 Reliability Analysis

Table 3. Reliability analysis of factors

\begin{tabular}{llll}
\hline \multicolumn{1}{c}{ Variables } & No. of Items & Number of respondents & Cronbach's Alpha \\
\hline Nutritional Information & 6 & 318 & 0.707 \\
Price & 5 & 318 & 0.613 \\
Country of Origin & 6 & 318 & 0.717 \\
Quality Standards & 5 & 318 & 0.803 \\
\hline
\end{tabular}

Table 4. Reliability analysis

\begin{tabular}{ll}
\hline Cronbach's Alpha & No. of Items \\
\hline 0.800 & 28 \\
\hline
\end{tabular}

Reliability test was done to assess the significance of data (J. Nunnally, 1978; J. C. Nunnally \& Bernstein, 1994). In above, table 3 the values of reliability test show acceptable results with all items included except for the price which is below 0.7 level so it is considered as not reliable value. The value of Cronbach's alpha for nutritional information, 
quality standard and country of origin is above 0.7 . The reliability of all the variables including dependent and independent variables is greater than the cut off value that is 0.70 which was good (Santos, 1999). In table 4 overall Cronbach's Alpha of the questionnaire was 0.800 . Which is significant as it is greater than the cut off value which is 0.7 .

\subsubsection{Confirmatory Factor Analysis Using AMOS}

Confirmatory factor analysis was performed using AMOS. Factor analysis was employed to reduce large number of variables to extract most underlying variables called factor. Confirmatory factor analysis is a useful method to examine the variability among observed variables and excerpt variability from items and load them into a common factor. As the study entails exploratory nature, factor analysis was done to identify the most important construct, i.e. Price Nutritional information, Quality Standard and Country of origin.

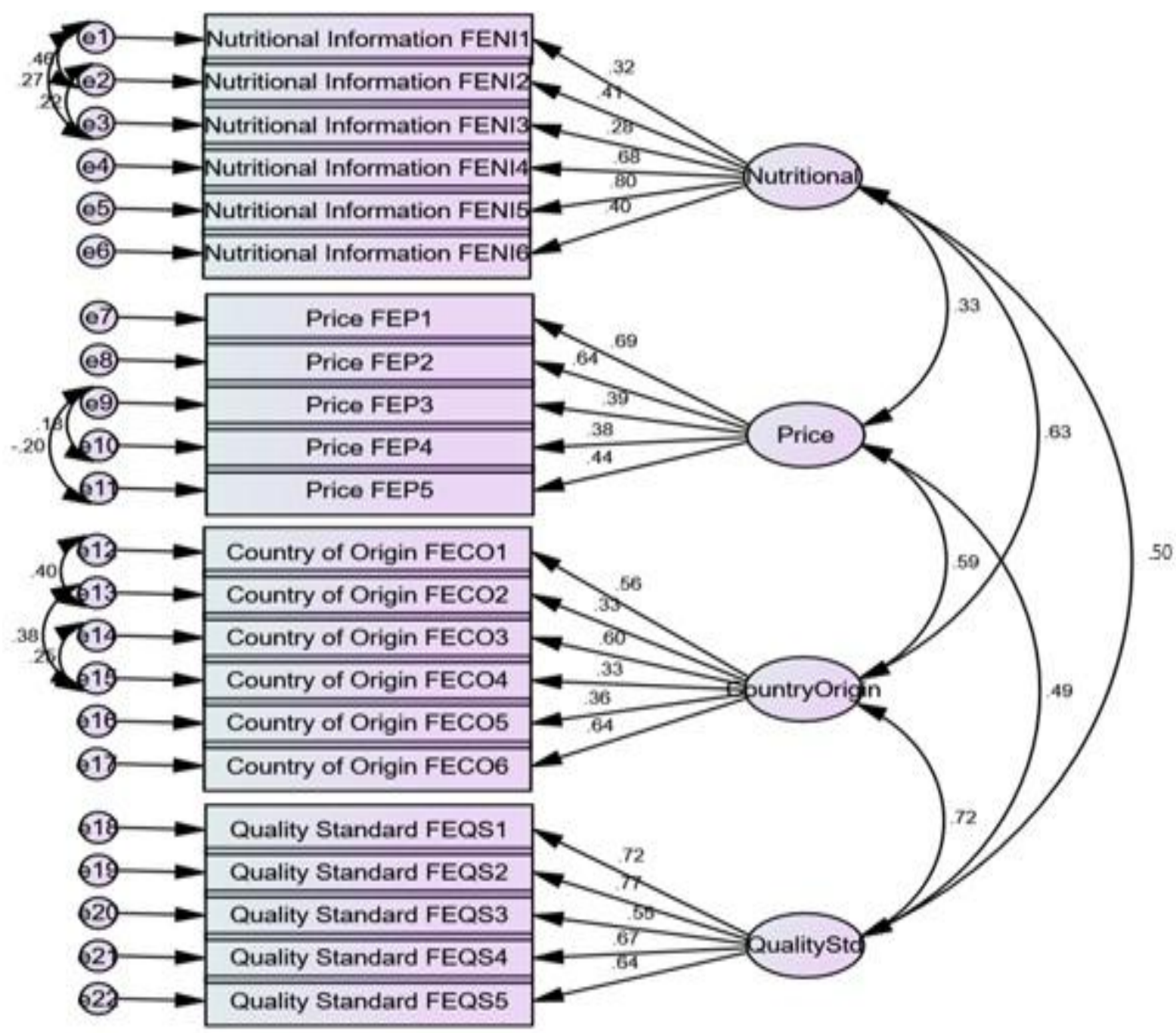

Figure 2. Confirmatory factor analysis using amos 
Table 5. Standardized regression weights

\begin{tabular}{|c|c|c|c|}
\hline $\begin{array}{c}\text { Latent } \\
\text { Variable }\end{array}$ & $\begin{array}{l}\text { Item } \\
\text { Label }\end{array}$ & Item Description & $\begin{array}{c}\text { Standardized } \\
\text { Factor Weights }\end{array}$ \\
\hline \multirow{6}{*}{$\begin{array}{l}\text { Nutritional } \\
\text { Information }\end{array}$} & FENI1 & $\begin{array}{l}\text { Verbal elements of the packaging attracts consumer's while } \\
\text { buying any product }\end{array}$ & 0.319 \\
\hline & FENI2 & $\begin{array}{l}\text { Verbal Elements of the packaging are important factor in high } \\
\text { involvement product category. }\end{array}$ & 0.408 \\
\hline & FENI3 & $\begin{array}{l}\text { Verbal Elements of the packaging are important factor in low } \\
\text { involvement category. }\end{array}$ & 0.277 \\
\hline & FENI4 & Nutritional Information impacts consumers buying behavior & 0.685 \\
\hline & FENI5 & $\begin{array}{l}\text { Nutritional Information about the milk gives consumers detailed } \\
\text { insight about the product inside. }\end{array}$ & 0.801 \\
\hline & FENI6 & Labeling of milk packaging is an important part of product. & 0.398 \\
\hline \multirow{5}{*}{ Price } & FEP1 & Pricing impacts consumers when making purchase. & 0.686 \\
\hline & FEP2 & Pricing impacts consumers when purchasing milk. & 0.640 \\
\hline & FEP3 & Does premium pricing impact milk sales? & 0.390 \\
\hline & FEP4 & Does lower price effect the success of milk? & 0.382 \\
\hline & FEP5 & Pricing and Brand's name impacts consumers buying behavior. & 0.437 \\
\hline \multirow{6}{*}{$\begin{array}{l}\text { Country of } \\
\text { Origin }\end{array}$} & FECO1 & Country-of-Origin impacts consumer's buying behavior. & 0.560 \\
\hline & FECO2 & Milk with country-of-origin's label attract consumers more. & 0.330 \\
\hline & $\mathrm{FECO} 3$ & $\begin{array}{l}\text { Countries with negative image impacts consumers buying } \\
\text { behavior. }\end{array}$ & 0.601 \\
\hline & FECO4 & Countries with negative image affect the milk sales. & 0.329 \\
\hline & FECO5 & $\begin{array}{l}\text { Eastern products over Western Products attract consumers more } \\
\text { while purchasing milk. }\end{array}$ & 0.364 \\
\hline & FECO6 & $\begin{array}{l}\text { Dairy Products with Halal tag regardless of any } \\
\text { country-of-origin impacts consumers buying behavior. }\end{array}$ & 0.642 \\
\hline \multirow{5}{*}{$\begin{array}{l}\text { Quality } \\
\text { Standard }\end{array}$} & FEQS1 & $\begin{array}{l}\text { Quality standards and protocols impacts consumer's } \\
\text { perceptions. }\end{array}$ & 0.718 \\
\hline & FEQS2 & Quality Standards plays vital role in milk category. & 0.766 \\
\hline & FEQS3 & $\begin{array}{l}\text { Milk with renowned brand name is priority of consumers while } \\
\text { making a purchase. }\end{array}$ & 0.548 \\
\hline & FEQS4 & Milk with good taste and smells impacts consumers. & 0.670 \\
\hline & FEQS5 & Quality packaging impacts consumers while purchasing milk. & 0.639 \\
\hline
\end{tabular}

The above table shows Standardized factor loading for each item and shows the association between individual items with the extract construct. Factor loading for each item depicts reasonable relationship with the underlying construct except for the nutritional information question 3 (i.e. FENI3), as it was also observed in Table 2 of descriptive statistics it achieved a lowest median value.

\subsubsection{Evaluating Measurement Model Fitness}

To evaluate the fitness of the proposed model, Amos delivers a set of useful indices that are used to determine the fitness and validity of the hypothesized model. Out of different significant indices, root mean square error of approximation (RMSEA), goodness of fit index (GFI), Chi-Square, CMIN/DF, adjusted goodness of fit index (AGFI), and comparative fit indices were observed to determine the authenticity of the research model. The discussed indices shows the degree to which constructs are related to one another, Table 6 and Figure 2 demonstrate the resultant values.

Table 6. Model fitness test

\begin{tabular}{ccc}
\hline Model Fit & Resultant Value & Threshold \\
\hline $\boldsymbol{\chi} \mathbf{( d f )}$ & 2.491 & $<3$ good; $<5$ Acceptable \\
CFI & 0.844 & Closer to 1; good \\
GFI & 0.877 & $>0.90$ \\
AGFI & 0.841 & $>0.90$ \\
RMR & 0.062 & $<0.08$ \\
RMSEA & 0.069 & $<0.08$ \\
PCLOSE & 0.000 & $>0.05$ \\
\hline
\end{tabular}


The measured values of CMIN/DF, RMR, and RMSEA are lying in threshold level, but PCLOSE is 0.000 for the Default model. Under the hypothesis of "close fit" the probability of getting a sample RMSEA as large as .069 is .000. While CFI, GFI, and AGFI are below threshold level but it is still acceptable.

\subsubsection{Structural Equation Modeling}

Structural equation modeling used to evaluate the structural relationship between exogenous and endogenous variables. The structural equation modeling includes factor analysis and multivariate analysis of the model. Firstly we evaluate the model fitness and measure whether the paths showing the relationship between measured and latent variables are significant or not. The path diagram showed in Figure 3. In this diagram nutritional information, price, quality standard and country of origin towards customer buying behavior. Besides table 8 shows the model fit results by analyzing model fit indices.

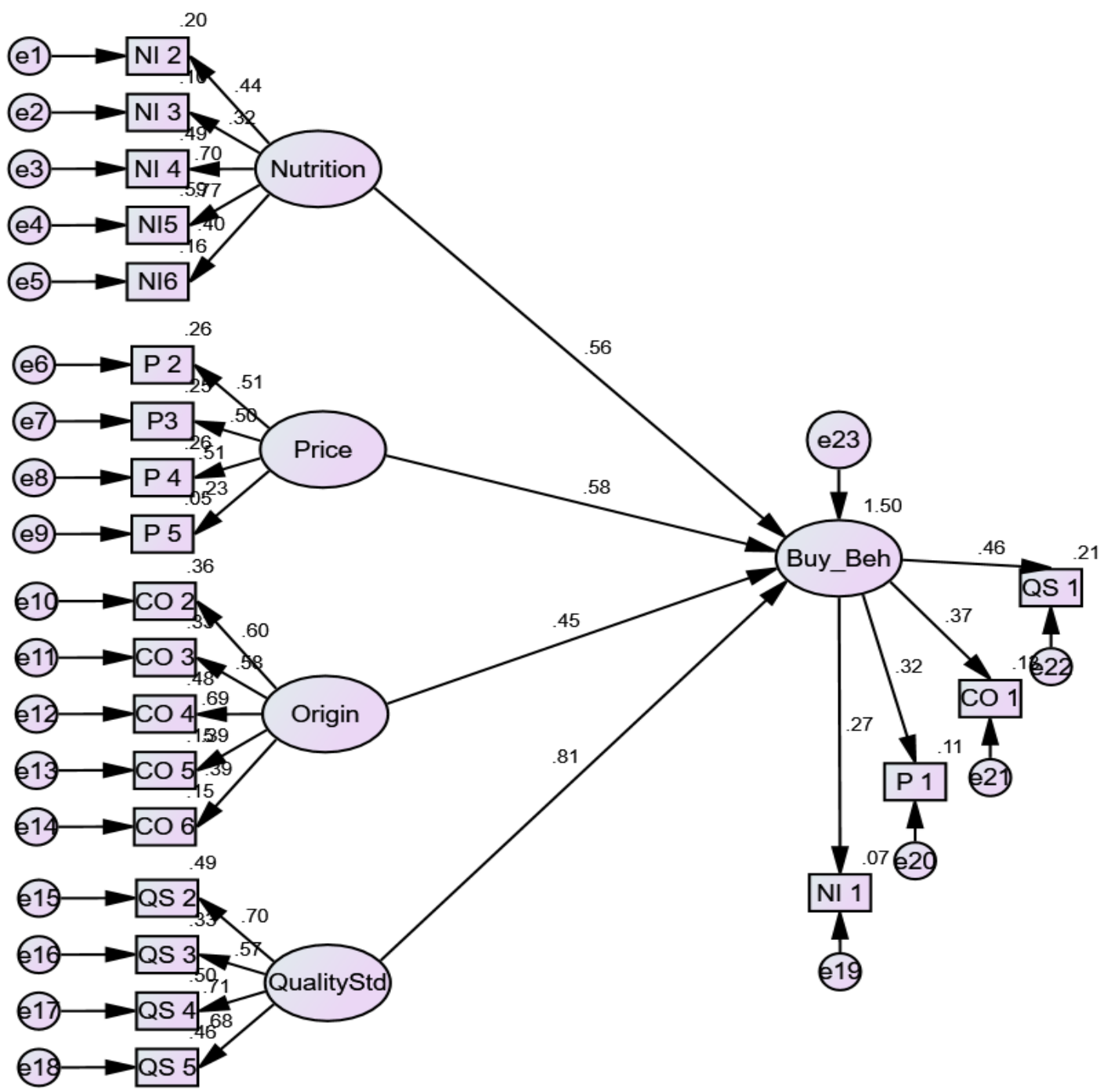

Figure 3. Path diagram

\subsubsection{Evaluating Measurement Model Fitness}

To evaluate the fitness of the proposed model, Amos delivers a set of useful indices that are used to determine the fitness and validity of the hypothesized model. Out of different significant indices, root mean square error of approximation (RMSEA), goodness of fit index (GFI), Chi-Square, CMIN/DF, adjusted goodness of fit index (AGFI), and comparative fit indices were observed to determine the authenticity of the research model. The 
discussed indices shows the degree to which constructs are related to one another. Table $7 \&$ Figure 3 demonstrate the resultant values.

Table 7. Model fitness test

\begin{tabular}{ccc}
\hline Model Fit & Resultant Value & Threshold \\
\hline P-Value & 0.000 & $<0.05$ \\
CMIN/DF & 4.825 & $<3$ good ; $<$ Acceptable \\
CFI & 0.579 & Closer to 1 ; good \\
GFI & 0.782 & $>0.90$ \\
AGFI & 0.731 & $>0.90$ \\
RMR & 0.132 & $<0.08$ \\
RMSEA & 0.110 & $<0.08$ \\
PCLOSE & 0.000 & $>0.05$ \\
\hline
\end{tabular}

There are different parameters to evaluate the goodness of a fit model. The study has adopted seven model fit indices to predict model fitness. Nutritional information, price, quality standard and country of origin towards customer buying behavior. As the $\mathrm{p}$ value is 0.000 which is less than 0.05 , thus model is fit for estimation. CMIN/Df value is below 5 which is also acceptable. However, for absolute fit, GFI should be greater than 0.9 and RMSEA would have value that falls within the range of 0.05 to 0.08 . As, in this model, these requirements are not fulfilled; thus, this model is not absolute fit. For CFI, it is not acceptable as well. But GFI and AGFI lies above 0.7 level it's also acceptable in some cases of model fit.

Table 8. Regression weights (hypothesis testing)

\begin{tabular}{|c|c|c|c|c|c|c|}
\hline & Estimate & SE & $\mathbf{C R}$ & $\mathbf{P}$ & Nature & Response \\
\hline Buy_Beh <--- Origin & 0.174 & 0.048 & 3.658 & $* * *$ & Positive & Accepted \\
\hline Buy_Beh <--- Quality Std. & 0.353 & 0.076 & 4.622 & $* * *$ & Positive & Accepted \\
\hline Buy_Beh <--- Price & 0.252 & 0.073 & 3.451 & $* * *$ & Positive & Accepted \\
\hline Buy_Beh <--- Nutritional inform. & 0.224 & 0.054 & 4.125 & $* * *$ & Positive & Accepted \\
\hline
\end{tabular}

First, 'Nutrition' has a significant impact on 'Buying Behavior' $(\beta=0.56, \mathrm{p}<.001)$, therefore H1 is accepted.

Second, 'Price' also has a significant impact on 'Buying Behavior', $(\beta=0.58, \mathrm{p}<.001)$, therefore H2 is accepted.

Third, 'Country of Origin' of the milk also seems to have an impact on 'Buying Behavior' $(\beta=0.45, \mathrm{p}<.001)$, therefore $\mathrm{H} 3$ is accepted

Fourth, 'Quality Standard' of the milk are also influencing the 'Buying Behavior' $(\beta=0.81, \mathrm{p}<.001)$, therefore H4 is also accepted.

\subsection{Discussions}

Results obtained from this research indicate that all four factors play a vital role when consumer is making purchase of milk. From above table 8 it is observed that highest critical ratio value is achieved by quality standard i.e. 4.622 and after that nutritional information stands out at second then origin and then comes price with critical ratio values $4.125,3.658$ and 3.451 respectively. The probability of getting a critical ratio as large as 4.622 in absolute value is less than 0.001 . In other words, the regression weight for quality standard in the prediction of buying behavior is significantly different from zero at the 0.001 level. The probability of getting a critical ratio for nutritional information as large as 4.125 in absolute value is less than 0.001 . The probability of getting a critical ratio for origin as large as 3.658 in absolute value is less than 0.001 . The probability of getting a critical ratio for price as large as 3.451 in absolute value is less than 0.001 .

Adam \& Ali (2014) classified these factors in terms of advertisements, branding and packaging. But in this research we have notice that all these factors have their own identity and impact on consumer buying behavior. Nutritional information, Price, Country of origin and Quality Standard all play a vital role during milk purchase. Since people in Karachi are getting more and more aware about the products and their sources since literacy level is increasing. People in Karachi are becoming more and more health conscious and try to suffice their needs with best possible 
solution that is available in the market. Since milk is most complex nutritional food, its adequate labelling is essential to aware consumers about their purchase. Labeling definitions differ and labeling may include a simple brand name, graphic or detailed product information (Philip Kotler K. L., 2008). On the other hand, consumers with their high involvement with the products tend to look at product information and make appropriate decisions accordingly and the product information could change their attitude of buying the product (Pinya Silayoi M. S., 2004).

Hong P.T.T. (2015) examined that people don't look at the price when purchasing milk, maybe it's because of its necessity for the family, no matter what the prices are in the market they would eventually buy it. But the result in this study shows that price also an important factor when purchasing milk, may be because consumers usually consider the higher prices as a superior product. Usually parents who have young kids they want to give the best quality food to their kids, and they may think that everything has its own price which they have to bear. Results also indicate positive trend on County of origin and Quality standard that consumers are now more looking into the origin and quality standards that milk producers followed. For big companies that produces milk, now they are taking these factors into accounts because it plays a crucial role in the marketing plan of the products, because if a products failed to communicate with the consumer at point of purchase then there is a chance that they would miss out an opportunity to sell the product.

Results from this research can be useful for branded segments that are out there in the market, it can be vital from one of the perspective of 7P's of marketing which is packaging. If they include adequate information about the product and give sufficient information that may induce a stimuli in consumer's minds that could possibly result in making purchase at point of sale. Since it is consider as a loss if consumer failed to put your product in the basket due to lack of communication from a producer, communication is very essential tool in the marketing, because if product itself fails to communicate with the shopper at shelf than there are few matters to look into, and packaging is one of them.

\section{Conclusion}

\subsection{Conclusion \& Implications}

The basic purpose of this research paper is to link the inter-play between different factors that effects buying behavior of consumers while analyzing data collected from urban areas of Karachi. The result of the finding shows a positive response of consumers towards the different factors when buying milk. Consumer prefer to look into every factor before buying milk with adequate labeling and enough amount of information provided on the packaging of the dairy product more specially when it comes to high involvement product category includes health care products and daily consumable items. Moreover, country of origin and prices also plays crucial role in consumer buying pattern.

The gaps that were identified, all of the previous researches were scattered in terms of factors and buying behavior and specially kinking all the variables to marketing and advertisements and packaging. This paper tends to bring all the factors relating to milk in one place and trying to give weightage to each factor of its own. Milk is considered as wholesome nutritional food so each factor which is considered in this paper has its own significant impact on consumer dynamics because every consumer has its own way of utilizing milk according to his/her needs. So in case of pricing when milk usage is bigger in terms of quantity consumers may shift towards cheaper source, but when it comes to infants feeding they might not look into pricing what is more important to them is nutritional components of the milk that are going to nourish the kids bodies.

Though this research was surrounded by many of the limitations which include limited time to complete the study, limited targeted audience, limited areas of Karachi and etc. Therefore, future research can be conducted on the relevant topic by opting other areas of Pakistan, choosing different industry other than Dairy industry, other research approach can be used in order to find better results. Since milk has its different usage so it may vary the relationship among factors and their weightage according to the product form.

\subsection{Limitation}

The main limitation of this study was only to cover a small part of the city, but they are well developed and most of respondents are well educated in that area. Also the time of conclude this study was limited so this study may not reflect all the consumers of the city. Also consumers with low education, low income and lower job profile were not included as a main part. Thus the result of the research could not be adequate.

\subsection{Future Research}

The future studies should explore the other research methodologies to bring out other factors. Furthermore, socio-economic conditions differ from house to house and their consumption patterns so it is important to expand the horizon of the research taking new consideration in accounts. It is also important for marketing managers to capitalize on these factors as well try to get engaged with consumers at the point of sale because the factors are highly correlated with buying behavior. 


\section{References}

Ahmed, S.A., \& Astous, A. (1995). Comparison of the country-of -origin effects on household and organizational buyers' product perception. European Journal of Marketing, 29(3), 35-51. https://doi.org/10.1108/03090569510145741

Alwis, A., Edirisinghe, J., \& Athauda, A. (2009). Analysis of Factors Affecting Fresh Milk Consumption Among the Mid-Country Consumers. Tropical Agricultural Research and Extension, 12(2), 103-109.

Amir, M., \& Ali, K. (2014). Impact of Verbal Elements of Packaging of Packaged. International Journal of Business and Social Science, 5(1).

Blackwell, R., Miniard, P., \& Engel, J. (2001). Consumer Behaviour. Ohio: South-Western.

Boniface, B., \& Umberger, W.M. (2012). Factors influencing Malaysian consumers' consumption of dairy products. Australian Agriculture \& Resource Economic Society.

Bousbia, A., Boudalia, S., Benidir, M., \& Belkheir, B. (2017). Analysis of factors affecting consumer behavior of dairy products in Algeria: a case study from the region of Guelma. International Journal of Agricultural Research, 12(2), 93-101. https://doi.org/10.3923/ijar.2017.93.101

Chao, P. (2001). The moderating effects of country of assembly, country of parts, and country of design on hybrid product evaluations. Journal of Advertising, 30(1), 67-81. https://doi.org/10.1080/00913367.2001.10673652

Chao, P., \& Rajendran, K.N. (1993). Consumer Profiles \& Perceptions: Country-of-Origin Effects. International Marketing Review, 10(2), 22-39. https://doi.org/10.1108/02651339310032534

Colonna, A., Durham, C., \& Meunier-Goddik, L. (2011). Factors affecting consumers' preferences for and purchasing decisions regarding pasteurized and raw milk specialty cheeses. Journal of Dairy Science, 94(10).

Devine, C.M. (2005). A Life Course Perspective: Understanding Food Choices in Time, Social Location, \& History. Journal of Nutrition Education and Behavior, 37(3), 121-128. https://doi.org/10.1016/S1499-4046(06)60266-2

Fulbright Economics Teaching Program. (2011-2012). Powder milk for children under 6 years old in Vietnam.

Goktolga, Z.G., Bal, S.G., \& Karkacier, O. (2006). Factors effecting primary choice of consumers in food purchasing: The Turkey case. Food Control, 17, 884-889. https://doi.org/10.1016/j.foodcont.2005.06.006

Gupta, G., \& Kumar, A. (2016). Role of Packaging in Influencing Consumer's Buying Behavior. International Journal of Research in Management, Science \& Technology, 4(3).

Hong, P.T.T. (2015). Factors influencing on purchasing formula milk for babies: An empirical research in Hanoi. International Journal of Business Administration, 6(5).

Insch, G.S., \& McBride, J.B. (2004). The impact of country-of-origin cues on consumer perceptions of produce quality: A bi-national test of decomposed country-of-origin contrast. Journal of Business Research, 57(3), 256-265. https://doi.org/10.1016/S0148-2963(02)00323-5

Ishida, A., Law, S.H., \& Aita, Y. (2003).Changes in food consumption expenditure in Malaysia. Agribusiness, 19(1), 61-76. https://doi.org/10.1002/agr.10038

Jain, A. (2010). Principles of Marketing. New Delhi: V.K. (India) Enterprises.

Johansson, J., \& Nebenzahl, I.D. (1986). Multinational Production: Effect on Brand Value. Journal of International Business Studies, 17(3), 101-126. https://doi.org/10.1057/palgrave.jibs.8490861

Keller, K.L. (2009). Choosing Brand Elements to build Brand Equity, In Strategic Brand Management (3rd ed.). Delhi: Dorling Kindersley.

Kumar, A., \& Babu, S. (2014). Factors Influencing Consumer Buying Behavior with Special Reference to Dairy Products in Pondicherry State. International Monthly Refereed Journal of Research in Management \& Technology, 3, 65-73.

Kurajdováa, K., Petrovićováa, J.T., \& Kašćákováa, A. (2015). Factors influencing milk consumption and purchase behavior - Evidence from Slovakia, Business Economics and Management. International Review of Management and Marketing, 5(1), 9-25.

Liana, M., Radam, A., \& Yacob, M.R. (2010). Consumer perception towards meat safety: confirmatory factor analysis. International Journal of Economics \& Management, 4(2), 305-318.

Maronick, \& Thomas, J. (1995). An Empirical Investigation of Consumer Perceptions of 'Made in the U.S.A.' Claims. International Marketing Review, 12(3), 15-30. https://doi.org/10.1108/02651339510091735

Nunnally, J.C. (1978). Psychometric theory (2nd ed.). New York, NY: McGraw-Hill. 
Nunnally, J.C., \& Bernstein, I.H. (1994). Psychometric theory (3rd ed.). New York, NY: McGraw-Hill, Inc.

Ong, F.S., Kitchen, J.P., \& Jama, A.T. (2008). Consumption patterns and silver marketing: an analysis of older consumers in Malaysia. Marketing Intelligence \& Planning, 26(7), 682-698. https://doi.org/10.1108/02634500810916663

Peter, J.P., \& Olson, J.C. (2008). Consumer Behavior and Marketing Strategy (8th ed.). New York: McGraw-Hill.

Philip Kotler, K.L. (2008). Marketing Management (13th ed.). New Jersey: Prentice Hall.

Pinya Silayoi, M.S. (2004). An exploratory study on the impact of involvement level and time pressure. British Food Journal, 106, 607-628. https://doi.org/10.1108/00070700410553602

Prescott, J., Young, O., O'Neill, L., Yau, N.J.N., \& Stevens, R. (2002). Motives for food choice: a comparison of consumers from Japan, Taiwan, Malaysia and New Zealand. Food Quality and Preference, 13, 489-495. https://doi.org/10.1016/S0950-3293(02)00010-1

Quah, S.H., \& Tan, A.K.G. (2010). Consumer Purchase Decision of Organic Food Products: An Ethnic Analysis. Journal of International Consumer Marketing, 22(1), 47-58. https://doi.org/10.1080/08961530902844949

Radam, A., Yacob, S.B., \& Selamat, J. (2010). Consumers' perceptions, attitudes and willingness to pay towards food products with "No Added Msg" labeling. International Journal of Marketing Studies, 2(1), 65-77. https://doi.org/10.5539/ijms.v2n1p65

Rezai, G., Mohamed, Z., \& Shamsudin, M.N. (2011). Malaysian Consumer's perceptive towards purchasing organically produce vegetable. Paper presented at the 2nd International Conference on Business and Economic Research, Holiday Villa Beach Resort and Spa, Langkawi, Kedah, Malaysia.

Rezai, G., Mohamed, Z., Shamsudin, M.N., \& Chiew, E.F.C. (2010). Non-Muslims' awareness of Halal principles and related food products in Malaysia. International Food Research Journal, 17, 667-674.

Santos, J.A.R. (1999). Cronbach's Alpha: A Tool for Assessing the Reliability of Scales. Journal of Extension, 37, $1-5$.

Senadisai, P., Trimetsoontorn, J., \& Fongsuwan, W. (2014). Model of Factors Influencing the Intention to Purchase Lactose-free Milk for the Population of Bankok. Research Journal of Business Management, 8(3), 284-293. https://doi.org/10.3923/rjbm.2014.284.293

Shaharudin, M.R., Pani, J.J., Mansor, S.W., Elias, S.J., \& Sadek, D.M. (2010). Factors Affecting Purchase Intention of Organic Food in Malaysia's Kedah State. Cross-Cultural Communication, 6(2), 105-116.

Shahbaz, R. (2015, May). Per capita income: A Pakistani now makes \$1,513 a year. The Express Tribune.

Sheng, T.Y., Shamsudin, M.N., Mohamed, Z.A., Abdullah, A.M., \& Radam, A. (2008). Food consumption behavior of the Malays in Malaysia. IIUM Journal of Economics and Management, 16(2), 209-219.

Solomon, M., Bamossy, G., Askegaard, S., \& Hogg, M.K. (2006). Consumer Behavior: A European Perspective (4th ed.). Harlow: Prentice Hall.

Solomon, M.R. (2006). Consumer behavior: buying, having and being (7th ed.). New Jersey, USA: Pearson Prentice Hall.

The National Dairy Council. (2008). Dairy: Food for Life. A Strategy to Promote Irish Milk \& Dairy Products 2008 2012

Tuan, L.T., Phuong, N.T.T., Ngoc, L.T.B., \& Mai, L.H. (2012). Powdered Milk Consumers' Buying Behavior. International Journal of Business and Management, 8(2). https://doi.org/10.5539/ijbm.v8n2p29

Valajoozi, M.R., \& Zangi, N.O. (2016). A review on visual criteria of pure milk packaging for parents and their children. British Food Journal, 118(1), 83-99. https://doi.org/10.1108/BFJ-12-2014-0425 